\title{
Effects of Maternal and Postweaning High-Fat Diet Exposure on the Hippocampal Functions and Morphology
}

\author{
Efectos de la Exposición de la Dieta Alta en Grasa Materna y \\ Pos Lactancia en la Función del Hipocampo y la Morfología
}

\author{
Yegin Bengi ${ }^{1} \&$ Ulupinar Emel $^{1,2}$
}

\begin{abstract}
YEGIN, B. \& ULUPINAR, E. Effects of maternal and postweaning high-fat diet exposure on the hippocampal functions and morphology. Int. J. Morphol., 36(3):1108-1117, 2018.

SUMMARY: Unbalanced nutrition during perinatal period causes varying degrees of perturbations in the metabolism and cognitive functions of offspring. The aim of this study was to investigate effects of maternal and postweaning high-fat diet (HFD) exposure on the growth parameters, hippocampal functions and morphology of offspring in a sex-dependent manner. Spraque-Dawley rats were fed either standard (10\% fat) or saturated-fat (65\% fat) diet during their gestation and lactation period. After weaning, pups were sustained in same diet for 6 more weeks. Body mass index (BMI) of pups were monitored weekly, then spontaneous locomotor activities were recorded. Spatial learning and memory functions were analyzed by Morris Water Maze (MWM) test. Total volumetric changes of hippocampal subfields were estimated by Cavalieri method. HFD exposure produced sex-dependent alterations in BMI, serum lipid and activity levels. MWM results showed no significant difference among groups. However, retrieval indexes were higher in HFD-fed males. Total volumetric analysis of the dentate gyrus was comparable, but the pyramidal cell layer volume of HFD-fed males was lower than those of SD-fed males. Despite alterations in some growth and lipid parameters, maternal and perinatal exposure to HFD did not markedly affect cognitive functions and hippocampal morphology of offspring.
\end{abstract}

KEY WORDS: High-fat diet; Morris Water Maze; Hippocampus; Activity meter; Cavalieri volume estimation.

\section{INTRODUCTION}

Dietary fat has a vital importance for the basal metabolism of organism, but unbalanced intake might threaten health and increase the risk of various diseases, such as noninsulin dependent diabetes mellitus, cardiovascular disease and stroke (Lin et al., 2017). Consumption of high fat diet (HFD) causes weight gain and obesity that constitute serious risk factors for developing metabolic syndrome (Buettner et al., 2007). Recent studies have also begun to reveal the effects of HFD exposure on the behavioral and cognitive functions. In both humans and experimental animals, elevated intake of saturated fat and sugar increase the incidence of Alzheimer's disease and other forms of cognitive dysfunction (Pasinetti \& Eberstein, 2008). Maternal consumption of HFD might affect development of the central nervous system in offspring and cause adverse effects on their learning and memory performances (Contu \& Hawkes, 2017).

It has been known that the hippocampus is preferentially susceptible to environmental insults and metabolic perturbations in comparison to the other brain regions. Its involvement in the higher order cognitive processes and modulation of complex behavioral activities makes this structure an important target site for neurotoxic and behavioral studies. To date, a number of studies have been published suggesting that HFD consumption impairs hippocampal dependent memory function (for a review, see Edlow, 2017). However, in these studies, there was a wide range of selection in the animal strain, age, sex, dietary fat amount and length of exposure. In some of the studies examining the developmental programming by maternal diet, dams were fed with HFD before mating, during pregnancy, only at the last week of gestation and/or into lactation (Page et al., 2014). Offspring born to HFD- or standard chow-fed dams were then either continued on HFD or maintained on the standard diet. Since hippocampal development spans both prenatal and early postnatal periods, duration of HFD exposure might diversely affect the complex patterns of gene expression during the hippocampal development and cause different disturbances on cognitive functions (Page et al.).

${ }^{1}$ Eskisehir Osmangazi University, Faculty of Medicine, Department of Anatomy, Eskisehir, Turkey.

${ }^{2}$ Eskisehir Osmangazi University, Health Science Institute, Interdisciplinary Neuroscience Department, Eskisehir, Turkey. 
In order to evaluate animal's learning and memory performances, different cognitive tests were used such as Morris Water Maze (MWM), Barnes maze, radial arm maze, Y-maze, T-maze, novel object recognition test and conditioned inhibition test. Among these tests, MWM is the most frequently used for testing the spatial learning and memory performances of animals. Besides, other brain regions such as prefrontal cortex, basal forebrain, striatum and cerebellum are also involved in various aspects of the MWM test. Since coordinated actions of different brain regions and neurotransmitter systems are required for the MWM performance, functional integrity of neural networks can be reliably investigated by using this test. Therefore, in this study, we aimed to investigate the effects of maternal and postweaning HFD exposure on the hippocampal learning and memory function of offspring by feeding them for 6 more weeks after weaning. After assessing the MWM performances of animals, we analyzed the volumetric changes of the hippocampus by using stereological methods in both female and male rats. We observed sex-dependent alterations in some of the growth parameters, hippocampal morphology and cognitive functions.

\section{MATERIAL AND METHOD}

Female Sprague-Dawley (weighing 200-250 g) that had never given birth were used for mating. All of the animals were maintained in a temperature-controlled environment $\left(22 \pm 2{ }^{\circ} \mathrm{C}\right)$, with 12 -h light/dark cycle. Experiments were done in accordance with the guidelines for Animal Care and Use of Eskisehir Osmangazi University, and were approved by the Local Ethical Committee for Animal Experimentations (protocol number: 202-2012). Following overnight mating, pregnant rats $(n=10)$ were identified by sperm positivity in their vaginal smears. Pregnant rats in the control group were fed a standard diet (SD) in which $10 \%$ of total calories were from fat (Table I), whereas experimental group were fed a HFD ( $65 \%$ of calories from fat) by absorbing $100 \mathrm{~g}$ SD with 30 $\mathrm{g}$ melted animal fat at warm temperature. After birth, the litters were culled up to eight pups (four females and four males in each litter) and housed together with their dams until weaning at postnatal day (P) 21 . To overcome the individual differences, two pups from each litter were selected randomly and each group contained 8 animals for each sex. After weaning offspring were maintained on their diet regimen for 6 more weeks.

To monitor the growth of animals, body weight and naso-anal length was measured on a weekly basis. The measurements were continued for 6 weeks. Body Mass Index (BMI) was calculated by dividing the body weight (grams) of animals by the body length squared (square centimeters).

All offspring were continued on their respective diets into adulthood, and at 63-64 days of age, their spontaneous locomotor activities were recorded. Both female and male animals were placed into an animal activity monitoring system consisting of a square Plexiglas box $(40 \times 40 \times 40 \mathrm{~cm})$ and activities of animals were recorded simultaneously by a video-computerized system (MAY 9803 Activity Monitor, Commat). All behavioral tests were conducted at the same time of day (from 9:00 to 12:00 a.m.) in a sound-isolated room under dim diffused lighting. During $15 \mathrm{~min}$ test period, stereotypic, horizontal, vertical, ambulatory and total number of movements, as well as the total traveled distance were measured as the total counts of beam interruptions in the sensors. The activity chamber was cleaned with $70 \%$ ethanol after each usage to eliminate any olfactory cues of the previously tested animal.

Using MWM test cognitive spatial ability of animals was tested as previously described at 65-69 days of age (Can et al., 2012). The water maze tank was $150 \mathrm{~cm}$ in diameter, and $60 \mathrm{~cm}$ in height. It was filled with $50 \mathrm{~cm}$ of water and water temperature was kept constant at $26-27^{\circ} \mathrm{C}$. The pool tank was divided into four equal quadrants. A round platform was placed $2 \mathrm{~cm}$ below the surface of the water and remained in the same quadrant throughout the experiment. The water was made opaque by mixing in milk powder to camouflage the escape platform. Each animal was subjected to four consecutive trials on each day with a gap of $5 \mathrm{~min}$. The rat was gently placed in the water of the pool between quadrants facing the wall of the pool with the drop location changing in each trial. The rats were allowed to swim a maximum $120 \mathrm{~s}$ (cut-off time) to find the hidden platform. Rats were allowed to remain on the platform for $20 \mathrm{~s}$. Time before finding the platform was recorded as the escape latency. If the rat did not escape within $120 \mathrm{~s}$ it was manually guided to the platform. After training completed, the animal was dried with a towel and returned to home cage. On day 5, the hidden platform was removed and retention testing (probe trial) was performed. The probe trial consisted of a $120 \mathrm{~s}$ free swim period without a platform. The time spent in the target quadrant (index of retrieval) was recorded.

Following the probe trials, the animals were anesthetized with halothane (2-Bromo-2-Chloro-1, 1, 1Trifluoroethane) via inhalation. Blood was collected by cardiac puncture. The blood samples are allowed to clot and were centrifuged at $3000 \mathrm{rpm}$ for $10 \mathrm{~min}$ to collect serum. Examples were immediately sent to the laboratory for examination of the serum lipid parameters. The serum 
Table I. Constituents of the standard diet pellet.

\begin{tabular}{lll}
\hline Ingredients & \% Ratio & Amount \\
\hline Dry Matter & $\%$ least & .88 \\
Raw Protein & $\%$ least & 14 \\
Crude Cellulose & $\%$ most & 11 \\
Ash & $\%$ most & .10 \\
HCL Insoluble Ash & $\%$ most & 2 \\
Calcium & least - most & $1.3-2.0$ \\
Phosphorus & $\%$ least & .1 \\
Na & $\%$ least - most & $0.5-1.0$ \\
NaCl & $\%$ most & 1 \\
Metabolic Energy &. & 2600 \\
Vitamins & & \\
Name & & $\mathrm{Unit}$ of \\
A & Amount & $\mathrm{IU} / \mathrm{Kg}$ \\
D3 & 10000 & $\mathrm{Mg} / \mathrm{Kg}$ \\
E & 1000 & \\
\hline
\end{tabular}

concentrations of total cholesterol (TC), high-density lipoprotein cholesterol (HDL-C), low-density lipoprotein cholesterol (LDL-C) and triglycerides (TG) were analyzed by the enzymatic colorimetric method using Roche kits (Reflotron; Roche Diagnostics, Mannheim, Germany).

After blood sample collection, the animals were transcardially perfused with $0.1 \mathrm{M}$ PBS (pH 7.4) and then fixed in $4 \%$ paraformaldehyde in phosphate buffer. Each brain, including the cerebellum and olfactory bulb, was dissected out, weighed, post fixed in $4 \%$ paraformaldehyde for two days, and then cryoprotected in a $30 \%$ sucrose solution in phosphate buffer. Serial horizontal sections were cut at a thickness of $200 \mu \mathrm{m}$ by using a vibratome (Pelco 10190; Ted Pella Inc., Redding, California, USA) along the entire hippocampus. Using a systematic random sampling method, every fourth section was mounted on poly-L-lysine-coated slides and air-dried at the room temperature. The sections were serially rehydrated in 96 , 90,80 , and $70 \%$ alcohol to distilled water and then stained with $0.1 \%$ hematoxylin-eosin solution for 4 minutes. Sections were briefly rinsed in distilled water, dehydrated in 70, 80, 90, and $96 \%$ ethanol, cleared in xylene, and covered with permanent mounting medium.

The Cavalieri method was used to estimate the total volume of the dentate gyrus and the pyramidal cell layer of the hippocampus. Sections were visualized under the light microscope of Stereo Investigator system (Version 9.0;
MicroBrightField Inc., VT, USA). A grid point scale was randomly positioned on each section, and the points hitting the dentate gyrus and the pyramidal cell layer of the interval hippocampus were counted twice. The sum of sectional areas of the layers was used to estimate total volume using the following formula:

$$
\mathrm{V}=\mathrm{t} \times \mathrm{SPi} \times \mathrm{a}(\mathrm{p})^{2} \mathrm{x} \mathrm{m}
$$

Where $\mathrm{V}$ is the total volume; $\mathrm{t}$ : The distance between two sections; SPi: The total counted number of points; a (p): The unit area associated with each grid point $\left(\mathrm{mm}^{2}\right)$; $\mathrm{m}$ : The section interval.

The data were acquired from eight animals for each group and analyzed by using a software program (GraphPad Prism 4.03, San Diego, CA, USA). BMI and escape latency values were evaluated by two-way repeated-measures ANOVA (with repetition as the within-subjects factor), followed by Bonferroni's method for multiple comparisons. Plasma lipid
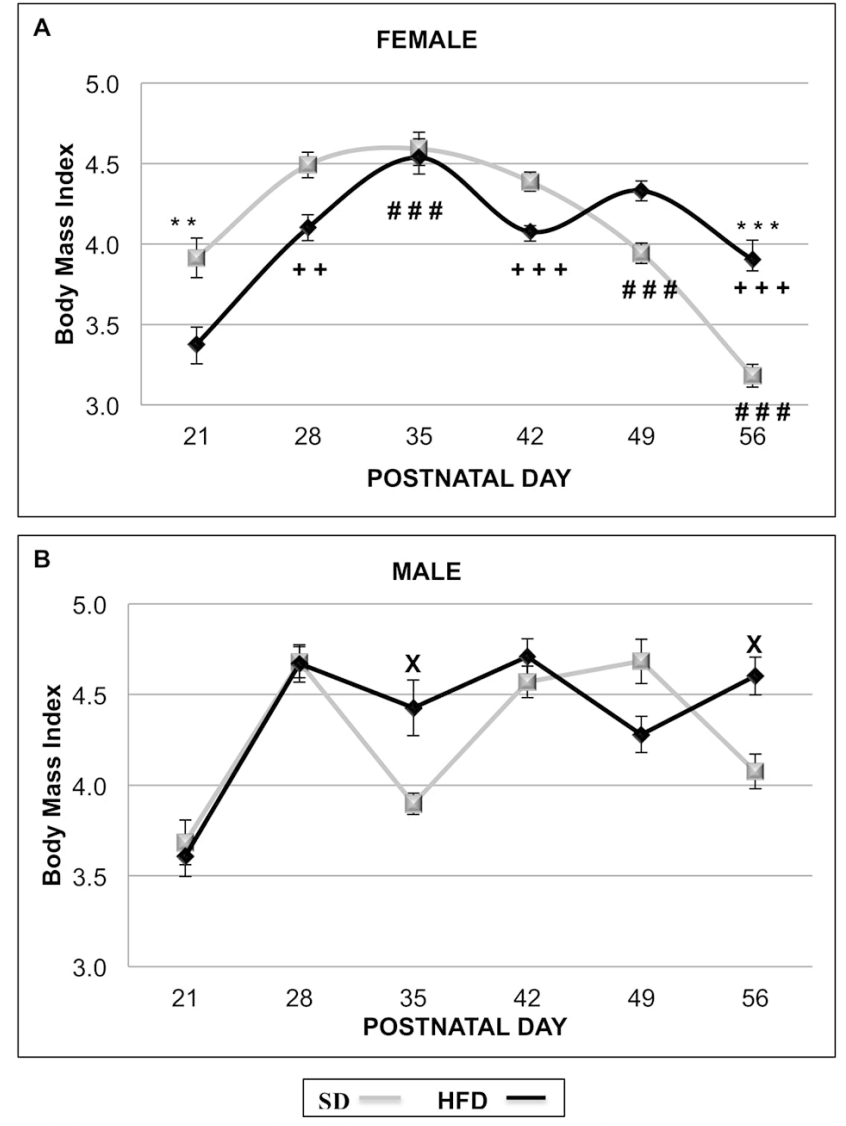

Fig. 1. The effects of high fat diet exposure on growth parameters of female and male offspring $(n=8)$. Values are presented as mean \pm SEM. $*$ : $p<0.05, * * *: p<0.001$ SD versus HFD in females. $\mathrm{x}: \mathrm{p}<0.05$ SD versus HFD in males. \#: $\mathrm{p}<0.05$, \#\#\#: $\mathrm{p}<0.001$ female versus male in SD group. + : $\mathrm{p}<0.05,+++$ : $\mathrm{p}<0.001$ female versus male in HFD group. 
parameters, MWM and the total volume of hippocampus subregions were analyzed by two-way analysis of variance (ANOVA), followed by a post-hoc Bonferroni's test. Experimental results were expressed as the mean \pm SEM. In all analyzes, $\mathrm{p}<0.05$ was accepted as the level of significance.
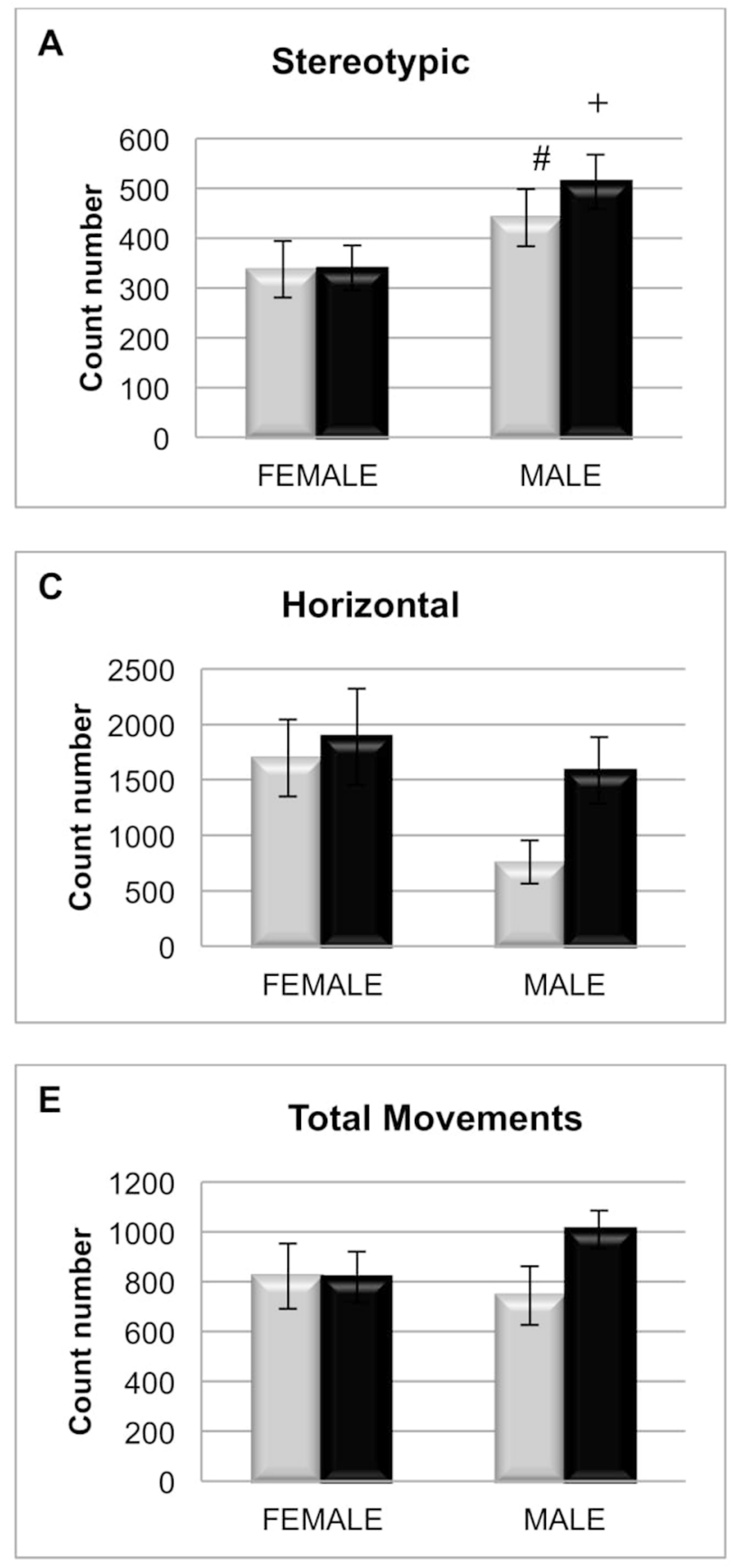

SD

\section{RESULTS}

Postweaning BMI of female offspring fed with SD was higher than HFD-fed animals, but after P49, a decrease
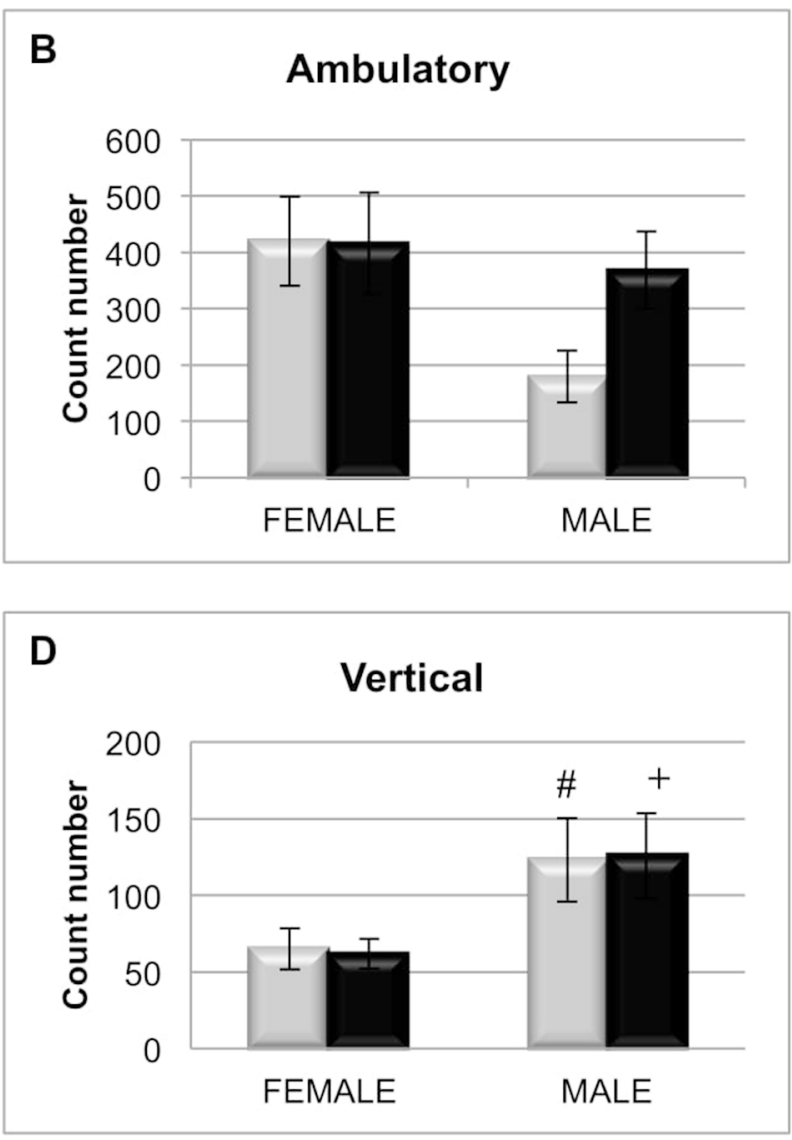

$\mathbf{F}$ Distance

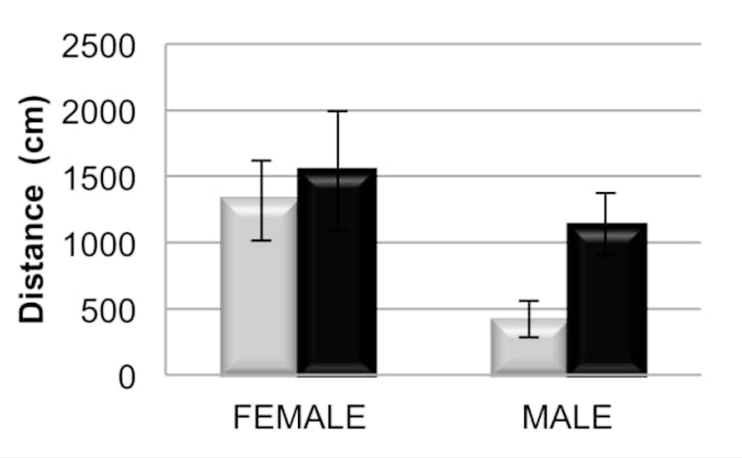

HFD

Fig. 2. The mean number of stereotypic (A), ambulatory (B), horizontal (C), vertical (D) and total movements (E), as well as the total distance traveled $(\mathrm{F})$ in the activitymeter are shown in the graphs. Values are presented as mean $\pm \mathrm{SEM}$. \#: $\mathrm{p}<0.05$ female versus male in SD group. $+: \mathrm{p}<0.05$ female versus male in HFD group. 
observed in their body weights. At the end of experimental period BMI of SD-fed animals was significantly lower $(\mathrm{p}<0.001)$ than those HFD-fed female animals (Fig. 1A). On the other hand, BMI of males were generally comparable, although at P56, BMI of HFD-fed males were significantly $(\mathrm{p}<0.05)$ higher than those SD-fed males (Fig. 1B). Therefore, two-way repeated measures of ANOVA results indicated a significant diet $\mathrm{X}$ sex interaction $[F(1.28)=13.74 ; p<0.001]$ in the weekly BMI values of animals.

Spontaneous locomotor activities of animals fed with either SD or HFD was comparable in both female and male offspring (Fig. 2A-F). However, when the effect of sex was compared by using two-way ANOVA, there was a significant difference in the stereotypic $[\mathrm{F}(1.28)=5.84 ; \mathrm{p}<0.05]$ and vertical $[F(1.28)=7.28 ; p<0.05]$ movements.
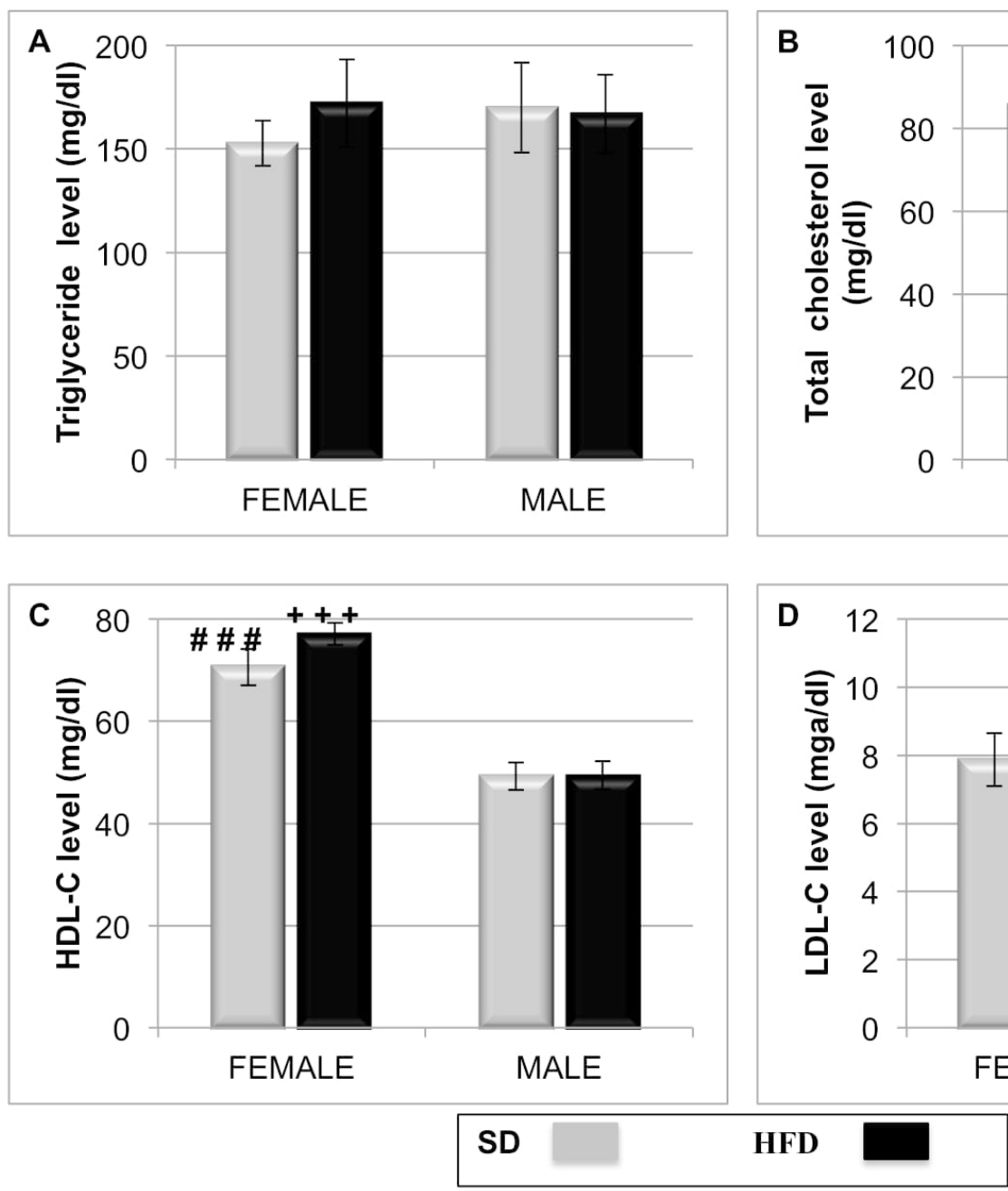

Fig. 3. Serum lipid parameters of offspring. Triglycerides (A), total cholesterol (B), HDL-C (C), and LDL-C levels (D) are shown in the graphs. Values are mean \pm SEM. \#: $\mathrm{p}<0.05$, \#\#\#:p <0.001 female versus male in SD. $+++: \mathrm{p}<0.001$ female versus male in HFD group. *: $\mathrm{p}<0.05$ SD versus HFD in females. 

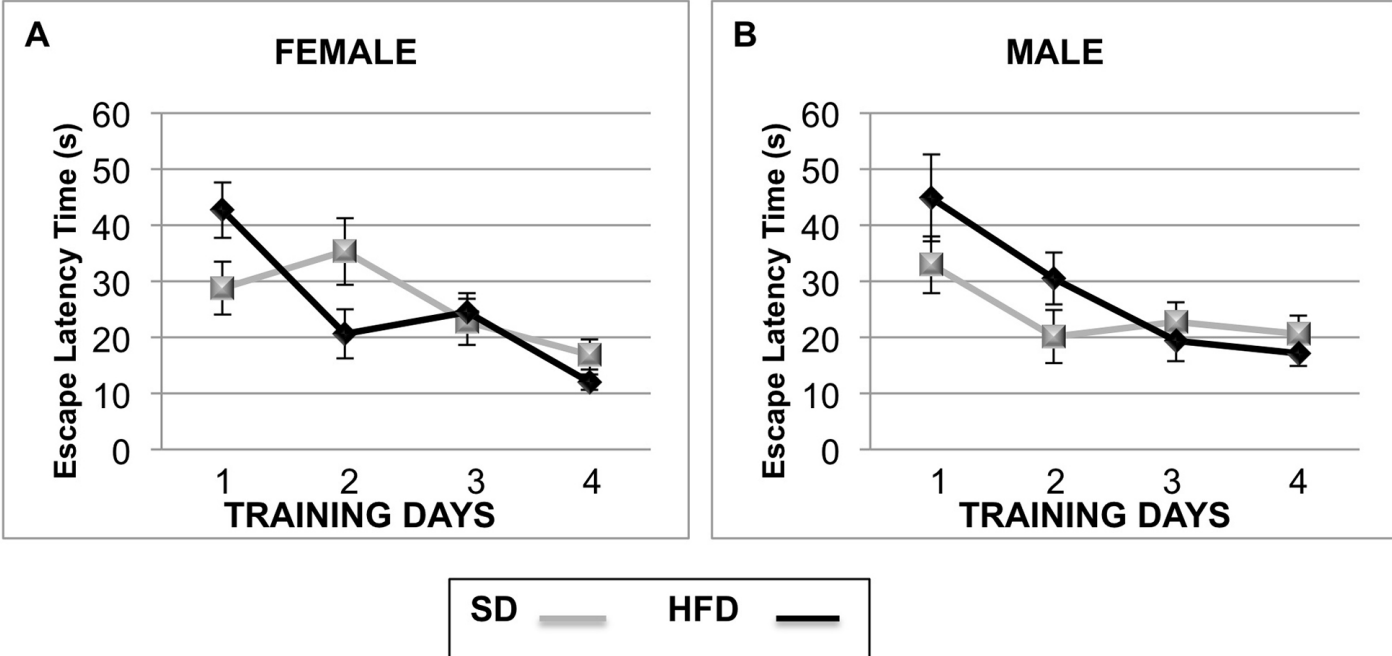

Fig. 4. Escape latency times in the MWM test. Two-way repeated measures of ANOVA revealed no significant dietsex interaction. Values are mean \pm SEM.

escape latency of offspring. On the other hand, post-hoc analysis with Bonferroni's test results showed that retrieval indexes of males, calculated as the mean time spent in target quadrant on day 5 , were significantly $(\mathrm{p}<0.05)$ higher in HFD-fed animals than those of SD-fed animals (Fig. 5). However, two-way ANOVA results showed no significant $\operatorname{dietXsex}$ interaction $[\mathrm{F}(1.28)=0.04 ; \mathrm{ns}]$.

Total volumes of the CA1, CA2, and CA3 subfields of the hippocampus and dentate gyrus were analyzed by using the Cavalieri method, and representative images are shown in Figure 6A. In females, no significant difference was observed in the total volume estimation of the granular and pyramidal cell layers of the hippocampus in SD- or HFDfed groups (Fig. 7A-B). In males, no significant difference was observed in the total volume estimation of the granular

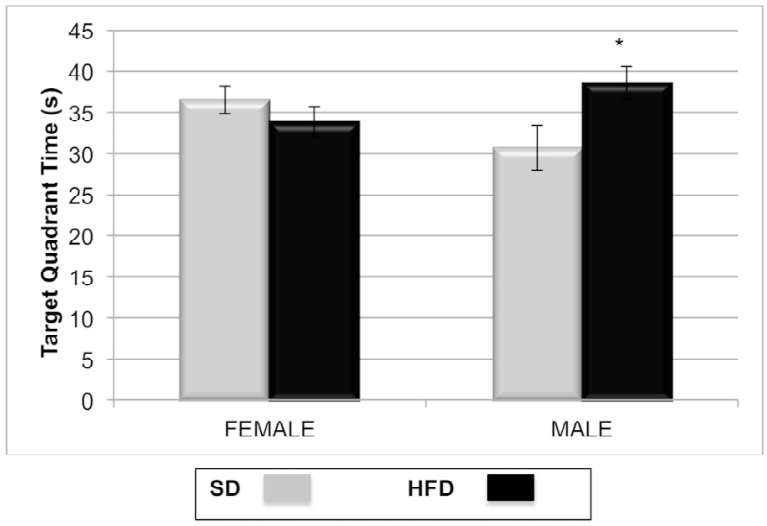

Fig. 5. Probe trial in the MWM test. HFD-fed males spent more time in the target quadrant relative to SD-fed males. Values are mean \pm SEM. *: $p<0.05$ HFD versus SD in males.

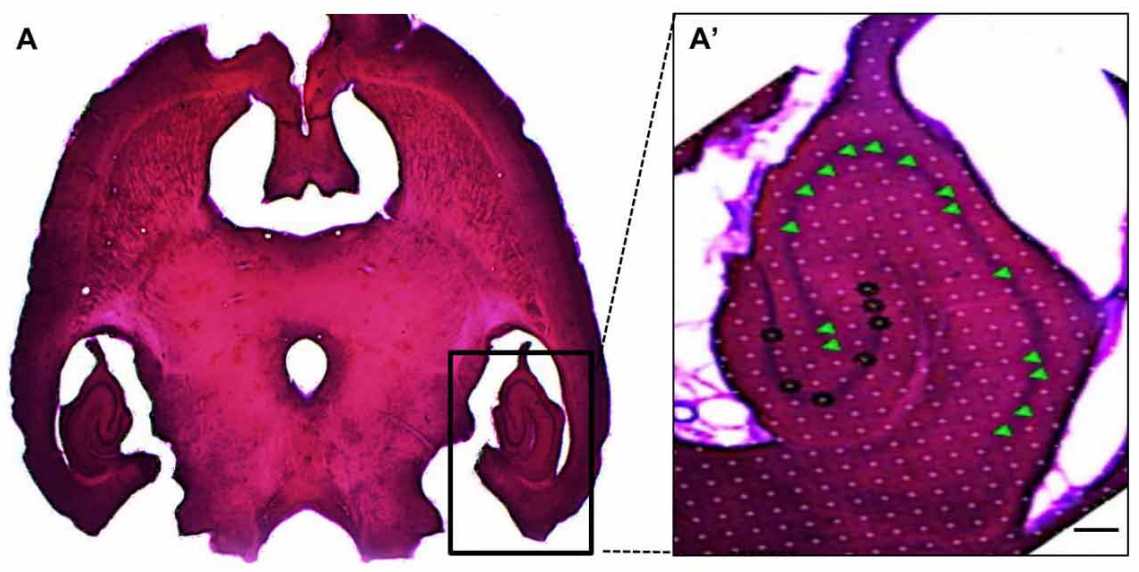

Fig. 6. A representative photomicrograph displaying sampling strategy in Cavalieri volume estimation method. Grid points corresponding to the pyramidal cell layer was indicated by green triangles and granular cell layer was indicated by black circles. Scale bar $=100 \mathrm{~mm}$ in A and $25 \mathrm{~mm}$ in $\mathrm{A}^{\prime}$. 
cell layer of hippocampus in SD- or HFD- fed groups (Fig. 7A). However, in males, estimated volume of the pyramidal cell layer was significantly $(\mathrm{p}<0.05)$ higher in SD-fed group than those of HFD-fed group (Fig. 7B).
Two-way ANOVA indicated no significant effect on $\operatorname{diet}[\mathrm{F}(1,28)=1.77 ; \mathrm{p}=0.19]$ and $\operatorname{sex}[\mathrm{F}(1,28)=0.01 ; \mathrm{p}=0.98]$; but a significant dietXsex interaction $[\mathrm{F}(1,28)=5.54 ; \mathrm{p}<0.05]$ in the volumetric estimation of the pyramidal cell layer.

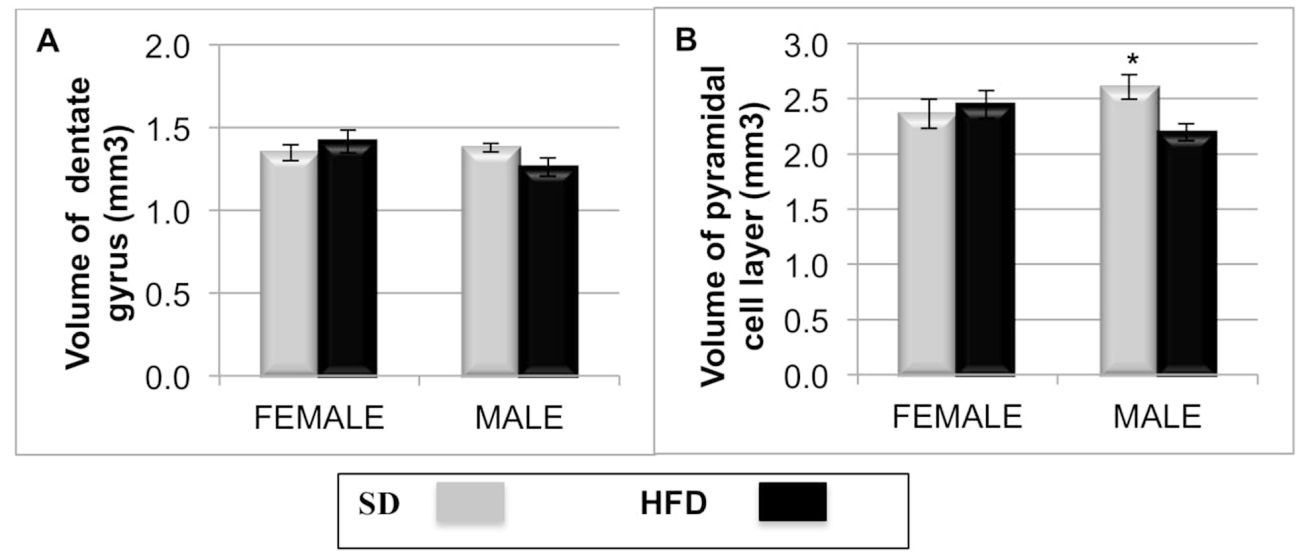

Fig. 7. Total volume estimation of dentate gyrus showed no significant difference between SD- and HFD-fed females (B), but volume of pyramidal cell layer was significantly higher in SD-fed males (C). $*: \mathrm{p}<0.05$ HFD versus SD in males.

\section{DISCUSSION}

In animals exposed to HFD during maternal and postweaning period, growth parameters, cognitive performances and the hippocampal morphology displayed some sex-dependent alterations. Studies in literature indicate that various metabolic effects might arise in experimental animals fed a diet containing 30 or higher percentages of fat as the source of energy. In these studies, it has been reported that long-term feeding with HFD causes 10 to $20 \%$ increase in the body weight in comparison to SD. A current metaregression analysis indicated that maternal HFD exposure did not affect birth weight, but increased the body weight gaining, adiposity, plasma lipid and insulin levels in both female and male offspring, although these effects differ markedly between models (Ribaroff et al., 2017). In our study, we did not observe significant alterations in the body weights of animals fed with HFD. The constituents of the fat used in our food pellet, differences in the duration and total calories of the diet might underlie in this divergence. Besides, the fluid nature of higher fat in the diet makes it difficult for the rats to eat. Cha et al. (2000) investigated the relationship between dietary fat contents and weight gain in adult male Sprague-Dawley rats and showed that body weight gains of animals fed the highest level (60\%) of dietary fat were lower than those fed lower $(44 \%)$ levels of dietary fat. In another study, Sprague-Dawley female rats fed an energy-rich palatable diet for seven months, only $1 / 3$ of animals developed obesity at the end of the overfeeding period, while others did not gain excess weight (Cattaneo et al., 1997).

The calculation of BMI is assumed as a standard measurement method in obesity diagnosis and follow-up. Therefore, we weekly monitored BMI of animals to compare the growth parameters of offspring born to HFD-fed mothers. Due to the differences in naso-anal length, both females and males in HFD-fed group displayed greater BMI than those of SD-fed group at the end of 10th week. Dunn \& Bale (2009) reported that maternal HFD exposure promotes body length increase in both first and second-generation offspring, but body weight increase does not extend to the second generation. This phenotype suggests that alterations in the body length can increase rapidly in concert with caloric availability and persists across generations. It has been also shown that, in mice, exposure to maternal HFD (4.73 kcal/ g) results in increased body size in third-generation offspring, but this effect was observed only in females and passed through the paternal lineage (Dunn \& Bale, 2011). Therefore, regulation of body size is controlled by many factors, while a broad program of epigenetic regulation would control the body length phenotype. 
Serum lipid parameters of males were comparable between HFD- and SD-fed groups. However, there was a significant sex and diet interaction in the total cholesterol and HDL levels. This difference was mostly due to the increase in LDL level of HFD-fed females. It has been shown that plasma concentrations of total cholesterol, phospholipids, free fatty acids and triglycerides significantly increase in HFD-fed mice as compared with controls (Kalaivanisailaja et al., 2003). There was a clearer increase in triglycerides and cholesterol levels in mice than in rats, and it is more pronounced in studies where HFD exposure is extended beyond the lactation period (Amin et al., 2011). In meta-analyses, male offspring lipid data show strong evidence for publication bias, whereas female offspring profiles are influenced by carbohydrate proportion of the diet (Ribaroff et al.). Although HFD can impair pancreatic function, reduce the number of insulin receptors and alter the glucose metabolism; high-fructose diet exposure has been shown to cause a higher increase in plasma triglyceride, cholesterol and insulin levels than those of high-fat exposure (Huang et al., 2004). Thus, the dietary constituents, as well as species and strain of animals, might diversely affect the metabolism and critically alter the outcomes.

Along with metabolic changes, current studies have also begun to emphasize the role of maternal diet in cognitive impairments, neurodevelopmental and psychiatric disorders in offspring (Contu \& Hawkes; Edlow). To examine the hippocampus-dependent functions of animals, we first evaluated spontaneous locomotor activity of offspring to confirm that exposure of HFD did not affect the physical activity levels of animals. Then, we measured the escape latency and retrieval index of animals in MWM test to assess their spatial learning and memory performances (Can et al.). We did not observe a significant difference in the spatial learning capacity of animals, but HFD-fed males displayed a better memory performance by spending more time in the target quadrant. Previous studies investigating the effects of maternal HFD in the performances of offspring in the MWM test showed different outcomes. In one study, White et al. (2009) studied the effects of prenatal and postnatal HFD (60\% fat) exposure on male Long Evans rats and evaluated their MWM performance at 20 weeks old. They observed no significant difference in the acquisition phase of test, but HFD progeny manifested a cognitive decline in the retention. In another study, Sprague-Dawley dams were fed a highsaturated fat diet, a high-trans-fat diet or a low-fat diet for 4 weeks prior to mating, through pregnancy and lactation, and MWM performances of progeny were assessed at adulthood (Bilbo \& Tsang, 2010). They showed that memory is significantly better in HFD groups, as females performed faster on training and males performed better in short-term probe trials. In contrast, Page et al. showed an impaired per- formance in learning and memory functions of SpragueDawley rats from HFD dams. In this study, dams were fed a diet high in saturated fat (45\% fat) during pregnancy and lactation. Offspring were weaned to either SD or HFD, and adult males (at 110-118 days of age) were tested for spatial learning and memory using MWM test. Interestingly, transition from HFD-fed dams to SD at weaning did not compensate for perturbations rendered during pre- and perinatal period. These discrepancies among different studies might be due to the diet contents or modifications in the testing protocols used in these studies, because the training durations were different in each study.

In a mouse model of maternal obesity, feeding of dams a HFD (32\% fat) leads to peroxidized lipid accumulation and impairment of hippocampal neurogenesis during the early life of their offspring (Tozuka et al., 2009). After weaning, feeding of pups with a SD impairs spatial learning and decreases the hippocampal BDNF levels at P21, but not at P70 days of age (Tozuka et al., 2010). Furthermore, while young offspring (at P35) show abnormal dendritic differentiation, adult mice (P84) do not show significant differences. These results suggest that abnormal hippocampal neurogenesis and cognitive functions in young HFD-offspring might be transient and placing the pups on a postweaning SD for a sufficient period of time might improve the neurogenesis level.

The hippocampus is an important area for spatial, contextual, and avoidance learning as well as memory processing. Neurogenesis, synaptogenesis and plasticity in the hippocampal formation are critical for these functions (Noble et al., 2014). In our study, we compared total volumes of granular and pyramidal cell layers of the hippocampus. While no significant difference was observed in the volume of dentate gyrus, the total volume of the pyramidal cell layer was lower in HFD-fed males than those SD-fed males. Within the dorsal hippocampus, especially the $\mathrm{CA} 3$ region of the pyramidal cell layer is important for memory retention, which likely involves both neurogenesis and long-term potentiation (Yassa et al., 2010). Previous studies have reported that pyramidal cell layer of hippocampus is more sensitive and dentate gyrus is more resistant to different environmental insults (Can et al.). Since dentate gyrus is an active proliferation site of the hippocampus, newly born neurons in this area can counterbalance the reduced plasticity of pyramidal cells. These neurons also have a unique property that exhibit robust long-term potentiation, thus they might facilitate new neurons to affect hippocampal network plasticity (Schmidt-Hieber et al., 2004). Page et al. showed that expression levels for the neurotropic factors, the major subunits of the hippocampal glutamate N-methyl-D-aspartate receptor channel (NR2A and NR2B) as well as 
synaptophysin were significantly decreased in response to maternal and postweaning HFD. It is possible that proliferation of granular neurons can compensate morphological alterations and deficits in the expression of key hippocampal genes following various environmental insults.

Morphological alterations in the hippocampus, including reduced neural progenitor cell proliferation, synaptic plasticity, losses of blood brain barrier integrity and dendritic arborization have been shown in other animal models of HFD exposure (Park et al., 2010). However, these alterations can be greatly affected by epigenetic modulations. In a study examining the effect of feeding adult Sprague-Dawley male rats a HFD (38\% fat) for 3 weeks, it has been shown that only the combination of HFD with physiological stress can cause atrophy in the apical dendrites of neurons in the CA3 region (Baran et al., 2005). Accordingly, Alzoubi et al. (2009) showed that only young adult male Wistar rats exposed to a combination of a HFD (25\% fat) and chronic psychosocial stress, but not chronic stress or HFD alone, display significantly impaired performance in probe trial of the radial arm maze test. From a human health perspective, it is important to note that exposure to HFD during early life is associated with complex patterns of gene expressions, morphological and behavioral alterations. However, deficits in the hippocampal morphology and functions seem to persist into adulthood in a sex-dependent manner. In future studies, detailed investigation of transgenerational effects of high dietary fat exposure and epigenetic modifications of phenotypes will shed light into these issues.

ACKNOWLEDGEMENTS: This study is supported by ESOGU-Scientific Research Projects Commission (ESOGU-BAP) with the grant number: 201211 D02.

YEGIN, B. \& ULUPINAR, E. Efectos de la exposición de la dieta alta en grasa materna y post lactancia en la función del hipocampo y la morfología. Int. J. Morphol., 36(3):1108-1117, 2018.

RESUMEN: La nutrición desequilibrada durante el período perinatal causa diversos grados de perturbaciones en el metabolismo y las funciones cognitivas en neonatos. El objetivo de este estudio fue investigar los efectos de la exposición a una dieta alta en grasas (HFD) materna y posdestete en los parámetros de crecimiento, las funciones del hipocampo y la morfología de neonatos de una manera dependiente del sexo. Ratas SpragueDawley fueron alimentadas con dieta estándar (10\% grasa) o grasa saturada (65\% grasa) durante su período de gestación y lactan- cia. Después del destete, las crías se mantuvieron en la misma dieta durante 6 semanas. El índice de masa corporal (IMC) de las crías se controló semanalmente, luego se registraron las actividades locomotoras espontáneas. El aprendizaje espacial y las funciones de memoria se analizaron mediante la prueba Morris Water Maze (MWM). Los cambios volumétricos totales de los subcampos del hipocampo se estimaron mediante el método de Cavalieri. La exposición a HFD produjo alteraciones dependientes del sexo en el IMC, los niveles de lípidos séricos y los niveles de actividad. Los resultados de MWM no mostraron diferencias significativas entre los grupos. Sin embargo, los índices de recuperación fueron más altos en machos alimentados con HFD. El análisis volumétrico total del giro dentado fue comparable, pero el volumen de la capa de células piramidales de los machos alimentados con HFD fue menor que el de los machos alimentados con SD. A pesar de las alteraciones en algunos parámetros lipídicos y de crecimiento, la exposición materna y perinatal a HFD no afectó marcadamente las funciones cognitivas y la morfología del hipocampo de la descendencia.

PALABRAS CLAVE: Dieta alta en grasa; Morris Water Maze; Hipocampo; Medidor de actividad; Estimación del volumen de Cavalieri.

\section{REFERENCES}

Alzoubi, K. H.; Abdul-Razzak, K. K.; Khabour, O. F.; Al-Tuweiq, G. M.; Alzubi, M. A. \& Alkadhi, K. A. Adverse effect of combination of chronic psychosocial stress and high fat diet on hippocampus-dependent memory in rats. Behav. Brain Res., 204(1):117-23, 2009.

Amin, K. A.; Kamel, H. H. \& Abd Eltawab, M. A. The relation of high fat diet, metabolic disturbances and brain oxidative dysfunction: modulation by hydroxy citric acid. Lipids Health Dis., 10:74, 2011.

Baran, S. E.; Campbell, A. M.; Kleen, J. K.; Foltz, C. H.; Wright, R. L.; Diamond, D. M. \& Conrad, C. D. Combination of high fat diet and chronic stress retracts hippocampal dendrites. Neuroreport, 16(1):3943, 2005.

Bilbo, S. D. \& Tsang, V. Enduring consequences of maternal obesity for brain inflammation and behavior of offspring. FASEB J., 24(6):2104$15,2010$.

Buettner, R.; Schölmerich, J. \& Bollheimer, L. C. High-fat diets: modeling the metabolic disorders of human obesity in rodents. Obesity (Silver Spring), 15(4):798-808, 2007.

Can, Ö. D.; Ulupınar, E.; Özkay, Ü. D.; Yegin, B. \& Öztürk, Y. The effect of simvastatin treatment on behavioral parameters, cognitive performance, and hippocampal morphology in rats fed a standard or a highfat diet. Behav. Pharmacol., 23(5-6):582-92, 2012.

Cattaneo, L.; De Gennaro Colonna, V.; Zoli, M.; Müller, E. E. \& Cocchi, D. Hypothalamo-pituitary-IGF-1 axis in female rats made obese by overfeeding. Life Sci., 61(9):881-9, 1997.

Cha, M. C.; Chou, C. J. \& Boozer, C. N. High-fat diet feeding reduces the diurnal variation of plasma leptin concentration in rats. Metabolism, 49(4):503-7, 2000.

Contu, L. \& Hawkes, C. A. A review of the impact of maternal obesity on the cognitive function and mental health of the offspring. Int. J. Mol. Sci., 18(5):E1093, 2017.

Dunn, G. A. \& Bale, T. L. Maternal high-fat diet effects on third-generation female body size via the paternal lineage. Endocrinology, 152(6):222836, 2011. 
Dunn, G. A. \& Bale, T. L. Maternal high-fat diet promotes body length increases and insulin insensitivity in second-generation mice. Endocrinology, 150(11):4999-5009, 2009.

Edlow, A. G. Maternal obesity and neurodevelopmental and psychiatric disorders in offspring. Prenat. Diagn., 37(1):95-110, 2017.

Huang, B. W.; Chiang, M. T.; Yao, H. T. \& Chiang, W. The effect of highfat and high-fructose diets on glucose tolerance and plasma lipid and leptin levels in rats. Diabetes Obes. Metab., 6(2):120-6, 2004.

Kalaivanisailaja, J.; Manju, V. \& Nalini, N. Lipid profile in mice fed a high-fat diet after exogenous leptin administration. Pol. J. Pharmacol., 55(5):763-9, 2003.

Lin, C.; Wu, X.; Zhou, Y.; Shao, B.; Niu, X.; Zhang, W. \& Lin, Y. Maternal high-fat diet programs cerebrovascular remodeling in adult rat offspring. J. Cereb. Blood Flow Metab., 1:271678X17731956, 2017.

Noble, E. E.; Mavanji, V.; Little, M. R.; Billington, C. J.; Kotz, C. M. \& Wang, C. Exercise reduces diet-induced cognitive decline and increases hippocampal brain-derived neurotrophic factor in CA3 neurons. Neurobiol. Learn. Mem., 114:40-50, 2014.

Page, K. C.; Jones, E. K. \& Anday, E. K. Maternal and postweaning highfat diets disturb hippocampal gene expression, learning, and memory function. Am. J. Phys. Regul. Integr. Comp. Physiol., 306(8):R527-37, 2014.

Park, H. R.; Park, M.; Choi, J.; Park, K. Y.; Chung, H. Y. \& Lee, J. A highfat diet impairs neurogenesis: involvement of lipid peroxidation and brain-derived neurotrophic factor. Neurosci. Lett., 482(3):235-9, 2010.

Pasinetti, G. M. \& Eberstein, J. A. Metabolic syndrome and the role of dietary lifestyles in Alzheimer's disease. J. Neurochem., 106(4):150314,2008

Ribaroff, G. A.; Wastnedge, E.; Drake, A. J.; Sharpe, R. M. \& Chambers, T. J. G. Animal models of maternal high fat diet exposure and effects on metabolism in offspring: a meta-regression analysis. Obes. Rev., 18(6):673-86, 2017.

Schmidt-Hieber, C.; Jonas, P. \& Bischofberger, J. Enhanced synaptic plasticity in newly generated granule cells of the adult hippocampus. Nature, 429(6988):184-7, 2004.

Tozuka, Y.; Kumon, M.; Wada, E.; Onodera, M.; Mochizuki, H. \& Wada, K. Maternal obesity impairs hippocampal BDNF production and spatial learning performance in young mouse offspring. Neurochem. Int., 57(3):235-47, 2010.

Tozuka, Y.; Wada, E. \& Wada, K. Diet-induced obesity in female mice leads to peroxidized lipid accumulations and impairment of hippocampal neurogenesis during the early life of their offspring. FASEB J., 23(6):1920-34, 2009.

White, C. L.; Pistell, P. J.; Purpera, M. N.; Gupta, S.; Fernandez-Kim, S. O.; Hise, T. L.; Keller, J. N.; Ingram, D. K.; Morrison, C. D. \& BruceKeller, A. J. Effects of high fat diet on Morris maze performance, oxidative stress, and inflammation in rats: contributions of maternal diet. Neurobiol. Dis., 35(1):3-13, 2009.

Yassa, M. A.; Stark, S. M.; Bakker, A.; Albert, M. S.; Gallagher, M. \& Stark, C. E. High-resolution structural and functional MRI of hippocampal CA3 and dentate gyrus in patients with amnestic Mild Cognitive Impairment. Neuroimage, 51(3):1242-52, 2010.

\author{
Corresponding author: \\ Prof. Emel Ulupinar \\ Eskisehir Osmangazi University \\ Faculty of Medicine \\ Department of Anatomy \\ 26480, Eskisehir \\ TURKEY
}

Email: eulupi@ogu.edu.tr

Received: 04-04-2018

Accepted: 31-05-2018 